\title{
COPD in Germany: Use of Diagnostic Measures Including Blood Eosinophil Counts in Daily Practice
}

\section{COPD in Deutschland: Einsatz diagnostischer Maßnahmen einschließlich der Blut-Eosinophilenzahl im Versorgungs- alltag}

\section{(ㄷ)(i) $(-$}

Authors

T. Greulich', V. Töpfer², M. Hennig ${ }^{3}$, C. C. Orehounig ${ }^{3}$, K. Ams³, C. D. Mohrlang³ P. H. Killian³, P. Kardos 4

Institutions

1 Department of Medicine, Pulmonary and Critical Care Medicine, University Medical Centre Giessen and

Marburg, Philipps-University Marburg, Member of the German Centre for Lung Research (DZL) Marburg, Germany

2 Pneumological Group Practice, Pulmonary Centre Ulm, Ulm, Germany

3 GlaxoSmithKline GmbH \& Co. KG, Munich, Germany

4 Group Practice and Centre for Allergy, Respiratory and Sleep Medicine, Red Cross Maingau Hospital, Frankfurt am Main, Germany

received 27.7.2020

accepted after revision 20.9.2020

published online 11.12 .2020

Bibliography

Pneumologie 2021; 75: 344-352

DOI 10.1055/a-1266-6602

ISSN 0934-8387

(C) 2020. The Author(s).

This is an open access article published by Thieme under the terms of the Creative Commons Attribution-NonDerivative-NonCommercial License, permitting copying and reproduction so long as the original work is given appropriate credit. Contents may not be used for commecial purposes, or adapted, remixed, transformed or built upon. (https://creativecommons.org/licenses/by-nc-nd/4.0/)

Corresponding author

PD Dr. med. Timm Greulich, Department of Medicine,

Pulmonary and Critical Care Medicine, University Medical

Centre Giessen and Marburg, Philipps-University,

Baldingerstraße, 35043 Marburg, Germany

greulich@staff.uni-marburg.de

Supplementary material

Details of the German doctor's questionnaire

(Arztfragebogen) available under

https://doi.org/10.1055/a-1266-6602

\section{ABSTRACT}

Background Accumulating evidence on the role of blood eosinophils as a biomarker prompted the Global Initiative for Chronic Obstructive Lung Disease (GOLD) committee to refine the existing treatment algorithm by incorporating eosinophil counts into treatment recommendations. However, there is a lack of data on when, why and how frequently such blood tests and other measures are being performed by German private respiratory specialists.

Methods A questionnaire evaluating doctors' opinions on the use of diagnostic measures at initial diagnosis and during follow-up, including blood eosinophil count in patients with COPD, was completed by 27 respiratory specialists. Medical records from the past 12 months of 251 patients treated by the same physicians were reviewed retrospectively to investigate the use of these measures.

Results Body plethysmography (100\% of doctors) and chest X-ray (96.3\%) were the most commonly used measures according to the doctor's questionnaire; other measures were COPD assessment test (CAT; $85.2 \%$ ) and blood eosinophil count $(81.5 \%)$. The evaluation of patients' medical records revealed that body plethysmography was performed in $72.7 \%$, the CAT in $61.8 \%$ and chest X-ray in $40.6 \%$ of patients. Blood eosinophil count was measured in $7.2 \%$. Conclusions In line with the GOLD recommendations, these results confirm that lung function, imaging and patient-reported outcome questionnaires play a crucial role in managing COPD. Our analyses reveal that measurement of the blood eosinophil count gained importance due to physicians' increased awareness of these cells as a useful biomarker. However, this test seems to be performed mainly for initial diagnosis and not on a regular basis.

\section{ZUSAMMENFASSUNG}

Einleitung Die zunehmende Evidenz zur Rolle der Eosinophilen im Blut als Biomarker veranlasste das Global Initiative for Chronic Obstructive Lung Disease (GOLD)-Komitee, den bestehenden Behandlungsalgorithmus zu verfeinern, indem die Bestimmung der Eosinophilenzahl in die Behandlungsempfehlungen aufgenommen wurde. Es fehlen jedoch 
Daten darüber, wann, warum und wie häufig solche Blutuntersuchungen und auch andere diagnostische Maßnahmen von pneumologischen Fachärzten in Deutschland durchgeführt werden.

Methoden Anhand eines Arztfragebogens wurde die fachärztliche Einschätzung von 27 Pneumologen zum Einsatz von diagnostischen Maßnahmen, einschließlich der Zahl der Eosinophilen, bei der Erstdiagnose und während des Verlaufs der COPD-Erkrankung evaluiert. Die medizinischen Aufzeichnungen von 251 Patienten dieser Ärzte wurden in einer 12-monatigen, retrospektiven Analyse ausgewertet, um die tatsächliche Anwendung dieser Maßnahmen zu untersuchen.

Ergebnisse Bodyplethysmografie (100\% der Ärzte) und Röntgen des Thorax (96,3\%) waren laut Arztfragebogen die Tests, die am häufigsten verwendet wurden. Weitere Maßnahmen waren der COPD Assessment-Test (CAT;
85,2\%) und die Messung der Zahl der Blut-Eosinophilen (81,5\%). Die retrospektive Auswertung der Patientenakten ergab, dass bei $72,7 \%$ der Patienten eine Bodyplethysmografie, bei $61,8 \%$ der CAT und bei $40,6 \%$ eine Röntgenaufnahme des Thorax durchgeführt wurde. Die Eosinophilenzahl im Blut wurde in 7,2\% gemessen.

Schlussfolgerungen In Übereinstimmung mit den GOLDEmpfehlungen bestätigen diese Ergebnisse, dass Lungenfunktion, Bildgebung und der Einsatz von Fragebögen zur Abbildung der Lebensqualität eine entscheidende Rolle bei der Behandlung von COPD spielen. Unsere Analysen zeigen, dass die Messung der Eosinophilenzahl im Blut aufgrund des zunehmenden Bewusstseins der Ärzte für diese Zellen als nützliche Biomarker an Bedeutung gewonnen hat. Dieser Test scheint jedoch hauptsächlich zur Erstdiagnose und nicht während des Verlaufs der Erkrankung durchgeführt zu werden.

\section{Introduction}

Chronic obstructive pulmonary disease (COPD) is a heterogeneous disease with varying phenotypes, i. e. clinical and pathophysiological differences in symptoms, airflow limitation, frequency of exacerbations and comorbidities [1]. According to current guidelines, COPD is associated with a permanent airflow limitation and an increased inflammatory response to inhalative noxae in the airways. The mainstays of COPD treatment are long-acting bronchodilators and, depending on the exacerbation risk, inhaled corticosteroids (ICS) [2,3]. Even though the European Medicines Agency concluded that the benefits of ICS medicines in treating COPD, i. e. reduction of exacerbations, continue to outweigh their risks [4], the concern of adverse effects, notably pneumonia [5] but also skin bruising, candidiasis, cataracts, osteoporosis and diabetes [6], is a constant matter of debate. The key challenge for physicians is to identify patients with the best benefit/risk profile in clinical practice. Therefore, the identification of a simple biomarker associated with a beneficial treatment response to ICS in COPD is gaining more interest. Chronic airway inflammation in COPD is usually neutrophilic but an elevated blood eosinophil count has been proposed as a potential biomarker of ICS responsiveness in COPD $[7,8]$. Within the past five years, numerous post-hoc analyses have consistently associated higher peripheral blood eosinophil counts with increased responsiveness of patients with COPD to ICS [9-11] or a worsening of exacerbation frequency after ICS withdrawal [12]. This relationship has been supported by results of more recently published secondary analyses, in which blood eosinophil count was shown to predict exacerbation risk and clinical response to ICS [13]. Furthermore, in an extended analysis of the IMPACT study [14], which investigated inhaled triple therapy compared with fixed-dose combination dual bronchodilators (long-acting beta-2 agonists [LABA]/long-acting muscarinic antagonists [LAMA] and ICS/LABA), the baseline blood eosinophil count was linked to an ICS-associated exacerbation reduction following a linear pattern. In the IMPACT study, the value of blood eosinophil count in the management of COPD was prospectively confirmed [15]. This accumulating evidence on the role of blood eosinophils as a biomarker prompted the Global Initiative for Chronic Obstructive Lung Disease (GOLD) committee to refine the existing treatment algorithm by incorporating eosinophil counts into treatment decisions. The 2020 revision of the GOLD report states that in exacerbating patients, ICS and bronchodilator combination therapy could be considered as a first-line option for patients with eosinophil counts of $\geq 300$ cells/ $\mu$ l [2]. With blood eosinophil count as a biomarker to be utilized for phenotyping and predicting treatment responses in COPD, there is a need to better understand when, why and how frequently such blood tests and other measures are performed in daily clinical practice.

The aim of this non-interventional study was to evaluate the attitudes of private German respiratory specialists towards the use of selected measures, including blood eosinophil counts, and the execution of these measures in routine clinical care of patients with COPD. We collected information on private German respiratory specialists' opinions on the use of diagnostic tests at initial diagnosis and during follow-up using a doctor's questionnaire (DQ). A retrospective evaluation of patient medical records was used to examine the actual execution of these tests within routine medical care in the respective private practices.

\section{Methods}

This German multicentre non-interventional study consisted of a cross-sectional questionnaire and a 12-month retrospective patient record study. The study was conducted from April 2018 to October 2018 (https://clinicaltrials.gov, NCT03465332) and was approved by the ethics committee of the Bavarian Medical Association in Germany.

The study consisted of a pilot study and two main parts. In the pilot study, respiratory specialists who were not participating in the survey tested the DQ and, based on the results, the 
DQ was revised (a translated version of the DQ details can be found in the supplement). During the first part of the main study, 27 private respiratory specialists were enrolled and data on their perspectives on the diagnosis and treatment of patients with COPD were collected via the DQ. The participating doctors were all respiratory specialists working in private practices, to whom patients in Germany were either referred or had direct access to.

Eligibility criteria for the participating doctors included more than ten years of experience in respiratory medicine, supervision of at least 500 COPD patients (at least 100 patients over the last 12 months), a focus on COPD, board certification as a respiratory physician, and informed consent to participate in this study and also share files of consenting patients (while complying with data protection rules).

In the second part, 251 patients with COPD were selected from participating doctors and retrospective medical data were collected from patient records. Each site was given a predefined minimum and maximum number of patients and a predefined recruitment window. Every consecutive patient visiting the site within the recruitment window, who met inclusion criteria and consented to participate in the study, was included. Inclusion criteria for patients comprised written informed consent, being $\geq 40$ years of age, a current or former smoker with $>10$ pack years, $\geq 12$ months since initial COPD diagnosis, no concurrent asthma diagnosis and $\geq 12$ months of documented disease history at participating study centres. Exclusion criteria for patients were pregnancy and breastfeeding (in the last 12 months), and patients currently participating in any interventional study and/or patients with severe comorbidities interfering with COPD therapy. In accordance with the study design, the physicians transferred existing retrospective data from selected patients who may have received any COPD medication into an electronic case report form (eCRF).

The primary endpoints were the assessment of the selection of the diagnostic tests, including blood eosinophil counts commonly used by private respiratory specialists in routine clinical care in Germany, and the reasons for the choice of these tests. Secondary endpoints included the investigation of any relationship between the blood eosinophil test selection (based on the DQ) and drug selection (based on information from the medical record review). Furthermore, comprehensive retrospective data were transferred from the patient records into the eCRF on the use of diagnostic measures, including lung function and imaging, patient-reported outcome (PRO) questionnaires (COPD assessment test [CAT], modified Medical Research Council [mMRC] dyspnea scale), COPD maintenance and other treatments in the previous 12 months, history of exacerbations, hospitalisation due to COPD and selected concomitant diseases. A COPD exacerbation was defined as a sustained worsening of respiratory symptoms that required treatment with systemic corticosteroids, antibiotics, or hospital admission, or any combination thereof.

Endpoints, including data from DQs and patient data, were analysed descriptively. If needed for certain explorative analyses, statistical tests were applied, appropriate to the level of measurement, e.g. the paired-samples t-test for continuous data or Fisher's exact test for categorical data. All tests performed are descriptive and have no confirmatory character; therefore, no correction for multiple tests was applied.

\section{Results}

\section{Doctors' perceptions of common diagnostic measure usage}

Twenty-seven centres participated in the study by completing the DQ and recruiting patients. At all sites, participating doctors were private respiratory specialists, who had treated at least 100 COPD patients in the previous 12 months; 19 sites (70.4\%) reported having treated over 1000 patients in the previous 12 months.

According to the DQ, assessment of lung function performed by body plethysmography was the most commonly used diagnostic measure by all respiratory specialists (100\%) ( $>$ Fig. 1). It was performed for diagnosis in 24 centres (88.9\%), regularly in 26 centres $(96.3 \%)$ and "when needed" in 5 centres (18.5\%) ( $\triangleright$ Table 1). All physicians considered that body plethysmography was useful as a diagnostic tool for COPD, as well as for monitoring of long-term therapy. The benefit for their patients was considered "high" by $92.6 \%$ of the physicians ( Table 1 ). Regarding spirometry, $88.9 \%$ of physicians stated that they usually use this method ( $\triangleright$ Fig. 1); either regularly (70.4\%) or for diagnosis (59.3\%). The most frequently named advantage of this measure was monitoring of short-term therapy, which was mentioned by $88.9 \%$ of the physicians.

Chest X-ray was the second most common diagnostic measure as stated in the DQ (96.3\%; $>$ Fig. 1) and was mostly considered as a test for diagnosis (81.5\%); over half of the physicians also used this for detection of concomitant diseases (59.3\%; - Table 1). Other frequently used measures were symptom and health-related quality of life assessment by CAT, the determination of alpha-1-antitrypsin deficiency (AADT), and measurement of the differential blood count, each considered by $85.2 \%$ of the physicians ( $\triangleright$ Fig. 1). Physicians reported that the CAT was completed regularly in $63.0 \%$ of cases and was mainly considered useful for monitoring the effects of long-term therapy (74.1\%), but also for monitoring of short-term therapy (63.0\%) and a useful diagnostic for COPD (55.6\%) ( Table 1). The eosinophil count was a blood test that was reported as "routinely used" by $81.5 \%$ of the respiratory specialists ( $\mathbf{F i g} \mathbf{1}$ ).

Further analysis of doctors' perceptions of blood eosinophil tests revealed that more than half of the respiratory specialists (59.3\%) reported that blood eosinophil counts were analysed for diagnosis ( Table 1). Only three physicians (11.1\%) indicated regular analysis of blood eosinophil counts. Two-thirds of respondents regarded blood eosinophils as a useful diagnostic tool for COPD and $55.6 \%$ felt it was an important diagnostic tool for concomitant diseases, followed by $29.6 \%$ of respondents who found it to be useful for monitoring of long-term therapy. The benefit of blood eosinophil counts for their patients was evaluated as medium (51.9\%) ( $\triangleright$ Table 1$)$.

The physicians were asked to add "other" assessment tests applied in their routine usage. In total, 36 additional tests were reported by 19 out of 27 physicians (70.4\%), with the 
Diagnostic measures*

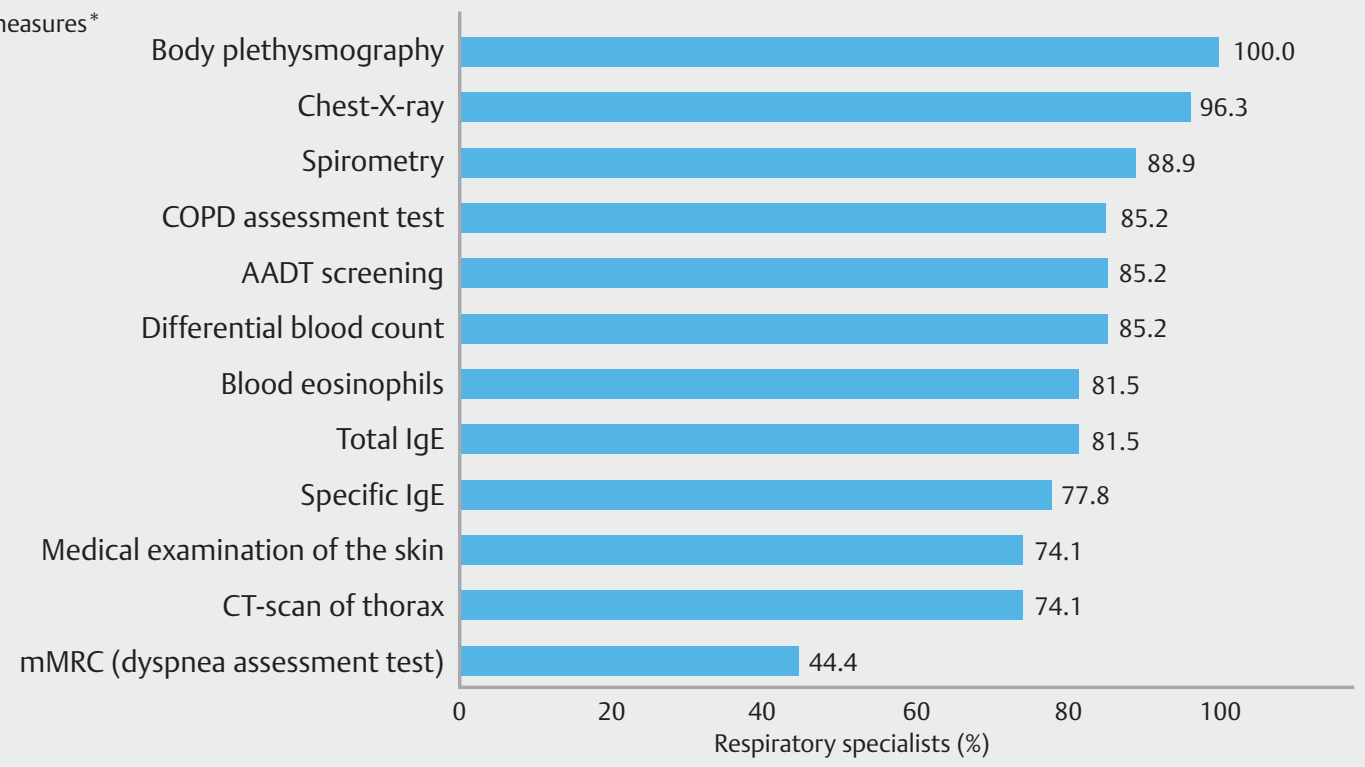

- Fig. 1 Diagnostic measures - results of the doctor's questionnaire (DQ). * Multiple responses were possible; AADT=alpha- 1 antitrypsin deficiency; $C T=$ computed tomography; IgE = immunoglobulin $\mathrm{E} ; \mathrm{N}=27$ (number of respiratory specialists)

- Table 1 Doctors' reasons for the use of diagnostic measures in routine clinical practice - results of the DQ

\begin{tabular}{|c|c|c|c|c|c|c|}
\hline \multirow[t]{2}{*}{ Diagnostic measures } & BP & Spirometry & Chest X-ray & CAT & mMRC & $\begin{array}{l}\text { Eosinophil } \\
\text { count }\end{array}$ \\
\hline & \multicolumn{6}{|c|}{$\begin{array}{l}\text { Respiratory specialists, } n(\%) \\
N=27\end{array}$} \\
\hline \multicolumn{7}{|l|}{ Time/frequency of execution * } \\
\hline For diagnosis & $24(88.9)$ & $16(59.3)$ & $16(59.3)$ & $12(44.4)$ & $7(25.9)$ & $16(59.3)$ \\
\hline Regularly & $26(96.3)$ & $19(70.4)$ & $14(51.9)$ & $17(63.0)$ & $6(22.2)$ & $3(11.1)$ \\
\hline When needed & $5(18.5)$ & $8(29.6)$ & $13(48.1)$ & $7(25.9)$ & $5(18.5)$ & $10(37.0)$ \\
\hline \multicolumn{7}{|l|}{ Advantages of this measure* } \\
\hline \multicolumn{7}{|l|}{ Diagnostic for... } \\
\hline - COPD & $27(100)$ & $20(74.1)$ & $22(81.5)$ & $15(55.6)$ & $15(55.6)$ & $18(66.7)$ \\
\hline - concomitant diseases & $13(48.1)$ & $8(29.6)$ & $16(59.3)$ & $4(14.8)$ & $4(14.8)$ & $15(55.6)$ \\
\hline \multicolumn{7}{|l|}{ Monitoring of... } \\
\hline - short-term therapy & $24(88.9)$ & $24(88.9)$ & $7(25.9)$ & $17(63.0)$ & $12(44.0)$ & $4(14.8)$ \\
\hline - long-term therapy & $27(100)$ & $23(85.2)$ & $13(48.1)$ & $20(74.1)$ & $15(55.6)$ & $8(29.6)$ \\
\hline Recommended by guidelines & $9(33.3)$ & $8(29.6)$ & $3(11.1)$ & $5(18.5)$ & $5(18.5)$ & $3(11.1)$ \\
\hline \multicolumn{7}{|l|}{ Benefit for the patient } \\
\hline None & 0 & 0 & $2(7.4)$ & $2(7.4)$ & $4(14.8)$ & $4(14.8)$ \\
\hline Low & 0 & $2(7.4)$ & $1(3.7)$ & $3(11.1)$ & $6(22.2)$ & $4(14.8)$ \\
\hline Medium & $2(7.4)$ & $10(37.0)$ & $11(40.7)$ & $17(63.0)$ & $11(40.7)$ & $14(51.9)$ \\
\hline High & 25 (92.6) & $15(55.6)$ & $13(48.1)$ & $5(18.5)$ & $6(22.2)$ & $5(18.5)$ \\
\hline
\end{tabular}


- Table 2 Patient demographics and disease characteristics

\begin{tabular}{|c|c|}
\hline Baseline & $\begin{array}{l}\text { Patients } \\
N=249\end{array}$ \\
\hline \multicolumn{2}{|l|}{ Sex, n (\%) } \\
\hline - Male & $144(57.8)$ \\
\hline - Female & $105(42.2)$ \\
\hline - Age (years), mean (SD) & $66.8(8.6)$ \\
\hline \multicolumn{2}{|l|}{ Age groups, n (\%) } \\
\hline . $<65$ years & $106(42.6)$ \\
\hline - $\geq 65$ years & $143(57.4)$ \\
\hline - Time since primary diagnosis (years), mean (SD) & $6.4(4.5)$ \\
\hline \multicolumn{2}{|l|}{ Time groups, n (\%) } \\
\hline - <2 years, n (\%) & $27(10.8)$ \\
\hline - $\geq 2$ years, $\mathrm{n}(\%)$ & $222(89.2)$ \\
\hline \multicolumn{2}{|l|}{ Smoking status at baseline, $\mathrm{n}(\%)$} \\
\hline - Ex-smoker & $160(64.3)$ \\
\hline - Current smoker & $89(35.7)$ \\
\hline \multicolumn{2}{|l|}{ Pack years (years), mean (SD) } \\
\hline - Ex-smokers & $33.9(18.0)$ \\
\hline - Current smokers & $35.7(15.5)$ \\
\hline \multicolumn{2}{|l|}{ Allergic comorbidities, n (\%) } \\
\hline - None & $233(93.6)$ \\
\hline \multicolumn{2}{|l|}{ Concomitant diseases (system organ classes), n (\%) } \\
\hline - Vascular (e. g. hypertension) & $133(53.4)$ \\
\hline - Respiratory (non-COPD), thoracic and mediastinal & $79(31.7)$ \\
\hline - Cardiac & $69(27.7)$ \\
\hline - None/unknown & $40(16.1)$ \\
\hline - Metabolic (e. g. diabetes mellitus) & $39(15.7)$ \\
\hline - Musculoskeletal & $32(12.9)$ \\
\hline - Endocrine & $23(9.2)$ \\
\hline \multicolumn{2}{|l|}{ GOLD $2017^{*}$ assessment of severity of obstruction, $n(\%)$} \\
\hline - GOLD I-mild & $15(6.0)$ \\
\hline - GOLD II-moderate & $126(50.6)$ \\
\hline - GOLD III-severe & $79(31.7)$ \\
\hline - GOLDIV-very severe & $29(11.6)$ \\
\hline \multicolumn{2}{|l|}{ GOLD $2017^{*}$ risk classes, A/B/C/D classification, n (\%) } \\
\hline - Group A: low risk & $34(13.7)$ \\
\hline - Group B: low risk & $136(54.6)$ \\
\hline - Group C: high risk & $42(16.9)$ \\
\hline - Group D: high risk & $37(14.9)$ \\
\hline
\end{tabular}

- Table 2 (Fortsetzung)

\begin{tabular}{|c|c|}
\hline Baseline & $\begin{array}{l}\text { Patients } \\
\mathrm{N}=\mathbf{2 4 9}\end{array}$ \\
\hline \multicolumn{2}{|l|}{ Retrospective 12 -month period } \\
\hline Exacerbations per patient, mean (SD) & $0.5(0.9)$ \\
\hline \multicolumn{2}{|l|}{ Number of exacerbations, n (\%) } \\
\hline .0 & $171(68.7)$ \\
\hline . 1 & $56(22.5)$ \\
\hline - $\geq 2$ & $22(8.8)$ \\
\hline \multicolumn{2}{|c|}{$\begin{array}{l}\text { COPD = chronic obstructive pulmonary disease; } \mathrm{SD}=\text { standard deviation } \\
{ }^{*} \text { Clobal Initiative for Chronic Obstructive Lung disease (GOLD) 2017; risk } \\
\text { classes based on COPD assessment test and exacerbations; } N=249 \text { (num- } \\
\text { ber of patients) }\end{array}$} \\
\hline
\end{tabular}

most frequently mentioned tests being blood gas analyses, other lung function tests (e. g. diffusion capacity) and bronchodilator reversibility tests (data not shown).

In addition to the evaluation of the commonly used measures, physicians were asked which tests they would classify as relevant biomarkers. A majority of 24 out of 27 physicians $(88.9 \%)$, considered blood eosinophil count to be a relevant biomarker for COPD. High-sensitive C-reactive protein was considered relevant by $13(48.1 \%)$ and total IgE determination by 10 physicians ( $37.0 \%$ ) (data not shown).

\section{Retrospective analysis of patient data}

Patient demographics and disease characteristics

The respiratory specialists recruited 251 patients, of whom two were excluded from analysis; one patient due to incomplete data and one patient due to a protocol deviation. The evaluable patient population therefore comprised 249 patients.

Detailed patient characteristics including comorbidities and exacerbations during the retrospective period are displayed in $(\triangleright$ Table 2). According to analysis of the medical records, a higher proportion of male than female patients were included in the study ( $57.8 \%$ vs. $42.2 \%$, respectively). The mean age was 66.8 years, with $42.6 \%$ of the patients being $<65$ years. More than half of the patients (64.3\%) had stopped smoking, while $35.7 \%$ were current smokers. About half of the patients $(50.6 \%)$ were categorised as having GOLD II disease (moderate severity with a percentage predicted forced expiratory volume in $1 \mathrm{~s}\left[\mathrm{FEV}_{1}\right]$ value between $50 \%$ and $79 \%$ ) and $31.7 \%$ of patients were classified in high risk GOLD groups C and D.

Within the retrospective 12-month period, the largest proportion of all documented COPD drugs was the combination of LABA and LAMA (18.6\%), followed by LAMA (16.8\%) and shortacting beta-2 antagonists (SABA) (16.5\%). ICS, given alone or combined with LABA and/or LAMA, represented $21.0 \%$ of the documented drugs (data not shown). 
- Table 3 Comparison of diagnostic measures between DQ and patient documentation based on patient population

\begin{tabular}{|c|c|c|c|c|}
\hline \multirow[t]{2}{*}{ Diagnostic measures } & \multirow{2}{*}{$\begin{array}{l}\text { Patients recruited by } \\
\text { physicians who reported } \\
\text { use of the measure }\end{array}$} & \multicolumn{2}{|c|}{ Patients in whom the measures were performed } & \\
\hline & & $\begin{array}{l}\text { Physicians who reported } \\
\text { routine use of the measure }\end{array}$ & $\begin{array}{l}\text { Physicians who reported } \\
\text { not to routinely use the } \\
\text { measure }\end{array}$ & \\
\hline & $N=249(\%)$ & $\%$ of patients & $\%$ of patients & P-value* \\
\hline Body plethysmography & $249(100)$ & 72.7 & - & $-{ }^{* *}$ \\
\hline Chest X-ray & $242(97.2)$ & 41.7 & 0 & 0.0436 \\
\hline Spirometry & $211(84.7)$ & 30.3 & 34.2 & 0.7035 \\
\hline COPD Assessment Test & 199 (79.9) & 67.8 & 38.0 & 0.0002 \\
\hline AATD screening & $210(84.3)$ & 1.0 & 7.7 & 0.0285 \\
\hline Differential blood count & $203(81.5)$ & 6.9 & 6.7 & 0.3171 \\
\hline Blood eosinophils & $192(77.1)$ & 8.3 & 3.5 & 0.3801 \\
\hline Total lgE & 199 (79.9) & 5.5 & 0 & 0.1274 \\
\hline Specific lgE & $197(79.1)$ & 4.6 & 0 & 0.2107 \\
\hline Medical examination of the skin & $185(74.3)$ & 3.2 & 4.7 & 0.6981 \\
\hline CT-scan of thorax & $183(73.5)$ & 6.6 & 4.5 & 0.7652 \\
\hline mMRC (dyspnea assessment test) & $107(43.0)$ & 50.5 & 0.7 & $<0.0001$ \\
\hline
\end{tabular}

\section{Diagnostic measures - patient documentation}

According to the retrospective data derived from patient records, body plethysmography was performed in $72.7 \%$ of all patients and spirometry in $30.9 \%$ of patients ( $\bullet$ Fig. 2 ). During the 12 months prior to inclusion in the study, the CAT was used for more than half of the patients ( $61.8 \%$ ), followed by chest $\mathrm{X}$-ray in $40.6 \%$ of patients and the mMRC dyspnea scale in $22.1 \%$ of patients. Blood eosinophil counts were performed in 18 patients (7.2\%).

The mean percentage of blood eosinophils in all 18 patients was $1.5 \%( \pm 1.3 \%)$. The proportion of patients receiving ICS was slightly higher among patients with blood eosinophil results than in patients without, especially when single ICS and/or orally administered prednisolone was given ( $22.2 \%$ vs. $11.3 \%$ and $22.2 \%$ vs. $10.0 \%$, respectively) (data not shown).

\section{Diagnostic measures - subgroup analysis}

The two different parts of the study ("DQ" and "patient data" [i.e. information from the medical record review]) were compared with each other. In some diagnostic measures (for example, the CAT and the mMRC dyspnea scale), the physicians' opinions of their routine use statistically significantly correlated with the retrospective data from the patient records ( Table 3 ). In contrast, the physicians' statements on other routinely performed diagnostic measures (including blood eosinophil count) were not reflected by their patients' documentation.

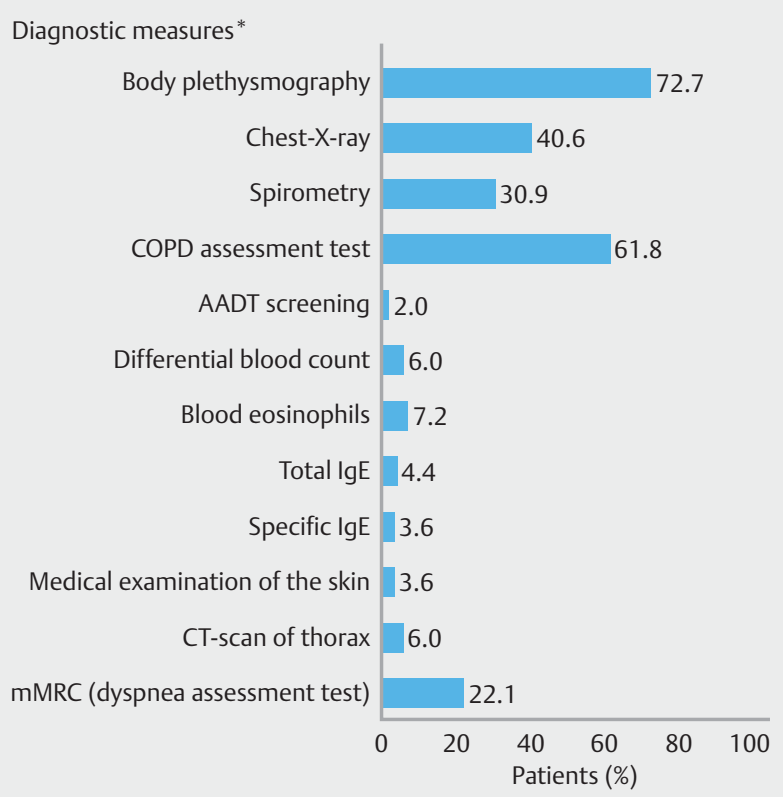

- Fig. 2 Diagnostic measures - patient documentation. *Multiple responses were possible; body plethysmography always included spirometry parameter; AADT = alpha- 1 antitrypsin deficiency; $\mathrm{CT}=$ computed tomography; $\mathrm{IgE}=$ immunoglobulin E; $\mathrm{N}=249$ (number of patients) 


\section{Discussion}

In accordance with current GOLD recommendations [2] our results confirm that lung function analysis plays a crucial role in diagnosing and monitoring COPD, since all physicians stated routine use of body plethysmography. Lung imaging by chest $X$-ray and PRO-questionnaires such as the CAT and (less frequently) the mMRC dyspnea scale were also commonly used measures, according to the DQ and the documented patient data. Our analysis revealed that blood eosinophil count gained importance due to increased physician awareness that blood eosinophils might qualify as a useful biomarker in COPD, since $88.9 \%$ of the physicians regarded them as such and $81.5 \%$ reported blood eosinophils to be a commonly used measure. However, according to the retrospective analysis of patient documentation, blood eosinophil counts were determined in only 18 out of 249 patients (7.2\%) in the observational phase from 19 April 2017 to 30 August 2018. This test was mainly performed for diagnosis and not on a regular basis. More than twothirds (66.7\%) of all physicians considered the blood eosinophil count to be an initial diagnostic tool for COPD and $11.1 \%$ reported its use as a regular assessment.

The study aimed to evaluate the availability, relevance and execution of diagnostic measures in real-life settings, which was accomplished by a cross-sectional DQ and the retrospective evaluation of patient data. One limitation of the study was the retrospective nature of the patient data analysis. Most importantly, at the time of data collection by the DQ, the role of eosinophils was much less pronounced than today. The international GOLD recommendations for using eosinophil counts in the treatment algorithm were published after completion of our study. As yet, the evidence base for using eosinophils in the COPD treatment algorithm is weak and the implementation of eosinophils as a biomarker in German recommendations for the treatment of COPD [3] is still ongoing. Therefore, it would be useful to repeat the study with the aim of collecting information about the changing perceived importance of blood eosinophils over time. On the contrary, the retrospective design can also be regarded as a strength because the actions taken by participating physicians were not influenced by the study design. In addition, a minimum set of inclusion and exclusion criteria allowed the enrolment of a representative set of practices and patients throughout Germany, with a broad range of COPD stages.

Although the number of analysed patients was relatively low, the patient characteristics in our study reflect that of a typical real-life COPD population. The patients recruited were very similar to the German DACCORD population, in which $49.2 \%$ of patients were categorized into the GOLD II stage at baseline $(50.6 \%$ in our study) and approximately three-quarters were free from exacerbations in the previous year (68.7\% in our study) [16]. The GOLD 2017 distribution of patients in our study was similar to that observed in the international COPD gene cohort and the European real-world population (Adelphi Real World Respiratory Disease Specific Programme) with 30\% of patients being categorized to high risk GOLD classes $C$ and D $[17,18]$. No comorbidities were recorded for only $16.1 \%$ of all patients. Vascular dis- orders (e.g. hypertension) and cardiac diseases were the most common concomitant diseases, as reported in other real-world studies [16-18].

Concerning lung function analysis, respiratory specialists stated regular use of body plethysmography (100\% usage) and spirometry $(88.9 \%)$ via the DQ. The retrospective analysis revealed that body plethysmography was performed in $72.7 \%$ of patients and spirometry in $30.9 \%$. As shown by the study eCRF, the body plethysmography panel mandatorily requested spirometry values. Thus, all patients underwent spirometry as recommended by both the GOLD and German guidelines. According to GOLD recommendations and the German guidelines, body plethysmography is not mandatorily recommended for diagnosis of COPD, but analysis of the complete set of lung volumes, including total lung capacity and residual volume, is important and may be necessary in some cases for further differential diagnosis [2,3]. Body plethysmography is available to respiratory physicians as an advanced diagnostic tool. It is mandatorily included in the reimbursement system of German secondary respiratory care. Therefore, it might be used more frequently than spirometry alone in German private respiratory practices, which has been reported before in other studies [19, 20].

In concordance with the current national and international COPD guidelines, chest X-ray was chosen for exclusion of differential diagnoses by $81.5 \%$ of all respiratory specialists and for the determination of concomitant diseases by $59.3 \%$. In the patient documentation, chest X-ray was performed in $40.6 \%$ of patients, which was assumed to be related to the fact that the first diagnosis of COPD for all patients was prior to the observation period of one year.

Other analyses that were not performed on a regular basis included alpha-1 anti-trypsin deficiency (AATD), medical examination of the skin, total immunoglobulin $E(\mathrm{IgE})$ and specific $\mathrm{IgE}$. While the latter three are used to rule out allergic disorders, the regular screening of COPD patients for AATD is recommended by national and international guidelines [2,3]. However, the disconnect between the recommendations and clinical practice has been published before [21].

Regarding the assessment of symptoms, the CAT was documented retrospectively in $61.8 \%$ of patients and the mMRC dyspnea scale in $22.1 \%$. Subgroup analyses, which aimed to examine whether the measures indicated in the DQ correlated to the patient data documented at the corresponding sites, revealed a significant association for both the CAT and mMRC dyspnea scale. Thus, the physicians' assessments of their routine usage did correlate with the documented patient data. It should be noted that the CAT, which was documented in a large proportion of patients, was stated in the DQ to be completed regularly. The use of the CAT is recommended by current guidelines and is a well-proven, quick, and reliable tool for the assessment of health-related quality of life [22].

In our study, the majority of physicians (88.9\%) stated that blood eosinophils are a relevant biomarker of COPD, as indicated in the DQ. According to the retrospective analysis, the blood eosinophil count was routinely performed in $7.2 \%$ of patients. In the DQ, most physicians reportedly performed the blood eosinophil count during initial diagnosis, which all patients under- 
went before inclusion in the study. This could explain the low utilisation of the blood eosinophil test. Nevertheless, a single analysis of blood eosinophil count at initial diagnosis would not be sufficient to guide the appropriate pharmacotherapy (e.g. to assign treatment with corticosteroids or not). Varying stability of blood eosinophils over time was shown in the German multicentre COSYCONET study [23], therefore regular analysis for all patients would be required to achieve concordant analyses. On the other hand, very recent analysis of the IMPACT trial revealed that two blood eosinophil count measurements do not appear to provide additional information to predict ICS treatment response in COPD versus one measurement [24].

The subgroup of 18 patients who underwent blood eosinophil testing in our study received more corticosteroids during the observational period (data not shown), thus the physicians showed a tendency towards drug selection based on blood eosinophil count. However, due to the low number of patients in that group, conclusions on the correlation of corticosteroid use and blood eosinophil count should be interpreted with caution.

The results of our study cannot be fully representative for the following two limitations: Firstly, the data collection time is referring to the years 2017-2018 and may likely not be representative for the actual situation. Secondly, even though we succeeded in including physicians with high expertise in the area, the doctor's questionnaire was completed exclusively by office-based, private respiratory specialists. Therefore, it is unclear to what extent the findings apply to routine clinical practice in German hospitals.

\section{Conclusion}

Our results confirm that lung function, imaging and the use of PRO questionnaires play a crucial role in diagnosing and monitoring COPD. Our analyses may suggest that that German respiratory physicians are aware of the role of blood eosinophil count in the future management of COPD, however, during 2017-2018 eosinophil count analysis was not yet implemented in German respiratory secondary care.

\section{Disclosures}

Writing support was provided by Dr. Angelika Schedel, Freelance Medical Writer located in Nuremberg, Germany. This support included the development of the first and subsequent drafts of the manuscript, under the guidance of the authors, and coordination of author comments and approval, and was funded by GlaxoSmithKline.

Trademarks are the property of their respective owners.

\section{Funding}

This study was funded by GlaxoSmithKline. 207733

\section{Acknowledgements}

The authors would like to thank the investigators and patients at the investigative sites for their support of this study.

\section{Competing interests}

Timm Greulich reports personal fees for advisory board meetings and lectures from AstraZeneca, Berlin-Chemie, Boehringer-Ingelheim, Chiesi, CSL-Behring, GlaxoSmithKline, Novartis and grants from Grifols and the German centre for Lung Research (DZL), Marburg, Germany, outside the submitted work.

Volker Töpfer has no conflict of interest to declare.

Michael Hennig, Christina C. Orehounig, Klaus Ams and Cordula D. Mohrlang are employed at GlaxoSmithKline $\mathrm{GmbH} \&$ Co, Munich, the sponsor.

Peter H. Killian was a full-time employee of GSK until 31st of March 2020 , which included conduction of the study and the preparation of the manuscript.

Peter Kardos reports personal fees for advisory board meetings and lectures from Astra Zeneca, Berlin-Chemie, Bionorica, Chiesi, Engelhardt, GlaxoSmithKline GmbH \& Co, Klosterfrau Health Care Club, Novartis, MSD, Schwabe Pharma Italia, conference participation was reimbursed by AstraZeneca and he is an investigator in a phase 3 MSD study, outside the submitted work.

\section{References}

[1] Han MK, Agusti A, Calverley PM et al. Chronic obstructive pulmonary disease phenotypes: the future of COPD. Am J Respir Crit Care Med 2010; 182: 598-604. doi:10.1164/rccm.200912-1843CC

[2] Global Initiative for Chronic Obstructive Lung Disease. Global Strategy for the Diagnosis, Management and Prevention of Chronic Obstructive Pulmonary Disease (GOLD). 2020. Im Internet (Stand: 16.6.2020): http://goldcopd.org/

[3] Vogelmeier C, Buhl R, Burghuber O et al. Guideline for the diagnosis and treatment of COPD patients - Issued by the German Respiratory Society and the German Atemwegsliga in Cooperation with the Austrian Society of Pneumology. Pneumologie 2018; 72: 253-308. doi:10.1055/s-0043-125031

[4] European Medicine Agencies (EMA), Pharmacovigilance Risk Assessment Committee (PRAC). Reviews known risk of pneumonia with inhaled corticosteroids for chronic obstructive pulmonary disease. Im Internet (Stand: 16.06.2020): https://www.ema.europa.eu/en

[5] Suissa S, Patenaude V, Lapi F et al. Inhaled corticosteroids in COPD and the risk of serious pneumonia. Thorax 2013; 68: 1029-1036. doi:10.1136/thoraxjnl-2012-202872

[6] Price D, Yawn B, Brusselle G et al. Risk-to-benefit ratio of inhaled corticosteroids in patients with COPD. Prim Care Respir J 2013; 22: 92100. doi:10.4104/pcrj.2012.00092

[7] Bafadhel M, Mc Kenna S, Terry S et al. Acute exacerbations of chronic obstructive pulmonary disease identification of biological clusters and their biomarkers. Am J Resp Crit Care Med 2011; 184: 662-671. doi:10.1164/rccm.201104-05970C

[8] Bafadhel M, Pavord ID, Russell REK. Eosinophils in COPD: just another biomarker? Lancet Respir Med 2017; 5: 747-759. doi:10.1016/ S2213-2600(17)30217-5

[9] Pascoe S, Locantore N, Dransfield MT et al. Blood eosinophil counts, exacerbations, and response to the addition of inhaled fluticasone furoate to vilanterol in patients with chronic obstructive pulmonary disease: a secondary analysis of data from two parallel randomised controlled trials. Lancet Respir Med 2015; 3: 435-442. doi:10.1016/ S2213-2600(15)00106-X 
[10] Siddiqui SH, Guasconi A, Vestbo ] et al. Blood Eosinophils: A biomarker of response to extrafine beclomethasone/formoterol in COPD. Am J Respir Crit Care Med 2015; 192: 523-525. doi:10.1164/ rccm.201502-0235LE

[11] Watz H, Tetzlaff K, Wouters EF et al. Blood eosinophil count and exacerbations in severe chronic obstructive pulmonary disease after withdrawal of inhaled corticosteroids: a post-hoc analysis of the WISDOM trial. Lancet Respir Med 2016; 4: 390-398. doi:10.1016/ S2213-2600(16)00100-4

[12] Chapman KR, Hurst JR, Frent SM et al. Long-term triple therapy deescalation to indacaterol/glycopyrronium in COPD patients (SUNSET): A randomized, double-blind, triple-dummy clinical trial. Am J Respir Crit Care Med 2018; 198: 329-339. doi:10.1164/rccm.201803$04050 C$

[13] Bafadhel M, Peterson S, De Blas MA et al. Predictors of exacerbation risk and response to budesonide in patients with chronic obstructive pulmonary disease: a post-hoc analysis of three randomised trials. Lancet Respir Med 2018; 6: 117-126. doi:10.1016/S2213-2600(18) 30006-7

[14] Lipson DA, Barnhart F, Brealey $\mathrm{N}$ et al. Once-daily single-inhaler triple versus dual therapy in patients with COPD. N Engl J Med 2018; 378: 1671-1680. doi:10.1056/NEJMoa1713901

[15] Pascoe S, Barnes N, Brusselle G et al. Blood eosinophils and treatment response with triple and dual combination therapy in chronic obstructive pulmonary disease: analysis of the IMPACT trial. Lancet Respir Med 2019; 7: 745-756. doi:10.1016/S2213-2600(19)30190-0

[16] Kardos P, Vogelmeier C, Worth $\mathrm{H}$ et al. A two-year evaluation of the 'real life' impact of COPD on patients in Germany: The DACCORD observational study. Respir Med 2017; 124: 57-64. doi:10.1016/j. rmed.2017.02.007
[17] Criner RN, Labaki WW, Regan EA et al. Mortality and exacerbations by Global Initiative for Chronic Obstructive Lung Disease groups ABCD: 2011 versus 2017 in the COPDgene cohort. Chronic Obstr Pulm Dis 2019; 6: 64-73. doi:10.15326/jcopdf.6.1.2018.0130

[18] Vestbo J, Vogelmeier CF, Small M et al. Inhaled corticosteroid use by exacerbations and eosinophils: a real-world COPD population. Int J Chron Obstruct Pulmon Dis 2019; 14: 853-861. doi:10.2147/COPD. S189585

[19] Glaab T, Banik N, Trautmann M et al. Guideline-conformity of outpatient COPD management by pneumologists. Pneumologie 2006; 60: 395-400. doi:10.1055/s-2006-932166

[20] Hellmann A, Hering T, Andres J. Expenditure on the care of COPD patients under everyday conditions in pneumological practices differentiated according to patients in chronic care and new patients and severity of the illness. Pneumologie 2018; 72: 437-445. doi:10.1055/ s-0043-120365

[21] Greulich T, Ottaviani S, Bals R et al. Alpha1-antitrypsin deficiency diagnostic testing and disease awareness in Germany and Italy. Respir Med 2013; 107: 1400-1408. doi:10.1016/j.rmed.2013.04.023

[22] Gupta N, Pinto LM, Morogan A et al. The COPD assessment test: a systematic review. Eur Respir J 2014; 44: 873-884. doi:10.1183/ 09031936.00025214

[23] Greulich T, Mager S, Lucke T et al. Longitudinal stability of blood eosinophil count strata in the COPD COSYCONET cohort. Int J of COPD 2018; 3: 2999-3002. doi:10.2147/COPD.S165909

[24] Bafadhel M, Barnes N, Bourke S et al. Analysis of IMPACT: is one blood eosinophil count measurement sufficient to predict ICS treatment response in COPD? Abstract 1358, ERS International Congress, 28 Sept-2 Oct Madrid, Spain. doi:10.1183/13993003.congress-2019. OA260 